\title{
The Growth and Photosynthetic Characteristics of Potato (Solanum tuberosum L.) Plantlets as Affected by Hydroponic Solution pH and EC, Light, and $\mathrm{CO}_{2}$
}

\author{
Xuan-Chun Piao, ${ }^{1}$ Debasis Chakrabarty, Eun- Joo Hahn and Kee-Yoeup Paek ${ }^{2}$ \\ Research Center for the Development of Advanced Horticultural Technology, Chungbuk National \\ University, Cheongju, Korea
}

\begin{abstract}
In vitro nodal cuttings of potato (Solanum tuberosum L.) 'Atlantic' and 'Russet Burbank' from bioreactor culture were hydroponically cultured for 28 days using a deep flow technique (DFT) system. The response of plant growth and photosynthesis to different levels of solution electrical conductivity $\left(\mathrm{EC} ; 0.08,0.15,0.22\right.$ and $\left.0.36 \mathrm{~S} \cdot \mathrm{cm}^{-1}\right)$ and $\mathbf{~ p H}(3$, $4,5,6$ and 7 ) were studied. The best growth, characters of shoot length, total shoot and root fresh and dry weight, were obtained in nutrient solution of pH 6.0 and $\mathrm{EC} 0.15 \mathrm{~S} \cdot \mathrm{cm}^{-1}$ for 'Atlantic', while $\mathrm{pH} 7.0$ and EC $0.15 \mathrm{~S} \cdot \mathrm{cm}^{-1}$ were found to be best for 'Russet Burbank'. Plantlet growth was reduced by low solution pH (3.0) and high EC level $\left(0.36 \mathrm{~S} \cdot \mathrm{cm}^{-1}\right)$. Photosynthetic rate, stomatal conductance, and transpiration rate were also found to be affected by EC levels. Down regulation of photosynthesis, as indicated by chlorophyll fluorescence results, were observed when potato plantlets were cultured under nutrient solution of higher EC level. Plantlet growth and photosynthetic rate increased as photosynthetic photon flux $(P P F)$ levels increased from 50 to $250 \mu \mathrm{mol} \cdot \mathrm{m}^{-2} \cdot \mathrm{s}^{-1}$. Particularly, increasing $P P F$ level had a more distinctive effect on plantlet growth than $\mathrm{CO}_{2}$ enrichment condition. It was apparent from this study that nutrient solution of $\mathrm{pH} 6.0$ and $0.15 \mathrm{~S} \cdot \mathrm{cm}^{-1} \mathrm{EC}$ in combination with high $P P F$ level $\left(250 \mu \mathrm{mol} \cdot \mathrm{m}^{-2} \cdot \mathrm{s}^{-1}\right)$ were suitable for hydroponic culture of potato plantlets as it would maximize net photosynthetic rate, and achieve the highest growth rates.
\end{abstract}

Plant tissue culture techniques have revolutionized plant propagation. Plants are micropropagated at the commercial level but the method is still costly, and handicapped because current in vitro procedures for acclimatization are still unsatisfactory in providing quality transplants for greenhouse or field(Ziv, 1995). The structure and function of micropropagated plants, as affected by various culture conditions unique to the in vitro environment, determines their ability to make the transition to the ex vitro environment. Plants grown in small culture containers are exposed to high levels of inorganic and organic nutrients, high relative humidity, elevated carbohydrate and growth regulator levels, low irradiance and limited $\mathrm{CO}_{2}$ and $\mathrm{O}_{2}$ exchanges. These factors contribute to high proliferation rates, but also interfere with acclimatization and transplanting stages, and cause low survival rates ex vitro. By modifying in vitro microenvironmental conditions (increasing photosynthetic photon flux, $\mathrm{CO}_{2}$ enrichment, number of air exchanges, etc.), a micropropagated plant's ability to survive after ex vitro transplant was improved (Cui et al., 2000; Hahn and Paek, 2001; Seon et al., 2000; Ziv, 1995). Modification of the in vitro production phases to more closely resemble ex vitro conditions will also contribute significantly to reduction in the cost, resources, space and energy, for micropropagation schemes. Micropropagated plants can be acclimatized simultaneous with rooting. A microponic culture system, combining micropropagation with hydroponics, has been applied to the mass production of chrysanthemum plantlets (Hahn et al., 2000). The enhanced plantlet growth, rooting and ex vitro acclimatization rates in microponic culture were proven to facilitate efficient transition from in vitro to ex vitro acclimatization. Yet, research concerning different physical and chemical microenvironmental conditions like $P P F$, $\mathrm{CO}_{2}$ concentration, $\mathrm{pH}$, and $\mathrm{EC}$ are necessary for practical use

This work was supported by Korea Science and Engineering Foundation (KOSEF) through Research Center for the Development of Advanced Horticultural Technology at Chungbuk National University, Cheongju, 361-763, Korea.

${ }^{1}$ Department of Horticulture, Agricultural College of Yanbian University, Longjing 133400, China.

${ }^{2}$ Corresponding author; email paekky@chungbuk.ac.kr. of this technique. EC and $\mathrm{pH}$ of the nutrient solution influences the rhizosphere environment, which in turn affects plant growth and photosynthesis. The optimum solution $\mathrm{pH}$ and $\mathrm{EC}$ would maximize photosynthesis, be conductive to optimum photosynthate partitioning, and achieve the highest growth rate (Hahn et al., 2000). Therefore, a better understanding of the effects of EC, $\mathrm{pH}, P P F$, and $\mathrm{CO}_{2}$ concentration on photosynthesis, plant growth and survival rate of propagules can help producers develop an optimal culture system. The objective of the present work was to examine the response of plant growth and photosynthesis at different $\mathrm{EC}$ and $\mathrm{pH}$ in combination with different $P P F \mathrm{~s}$.

\section{Materials and Methods}

Plant material AND Culture System. Plantlets of Solanum tuberosum L. 'Atlantic' and 'Russet Burbank' from bioreactor culture (Piao, 2002) were cut into 4 to $5 \mathrm{~cm}$ pieces (shoot apex including two nodes), eight of which were planted in a square plastic box $(29 \times 23.5 \times 17.5 \mathrm{~cm}$, Daekwang Ind. Co., Yongin, Korea). They were grown in nutrient solution (Yamazakis, 1984) for $30 \mathrm{~d}$ using deep flow technique (DFT) system. The nutrient solution contained $\mathrm{NH}_{4}{ }^{+} \mathrm{N}, \mathrm{NO}_{3}{ }^{-} \mathrm{N}, \mathrm{P}, \mathrm{K}, \mathrm{Ca}$, and $\mathrm{Mg}$ at $1,6,2,4,2$, and $2 \mathrm{mg} \cdot \mathrm{L}^{-1}$, respectively as macronutrients. Micronutrients of the solution were composed of Fe, B, Mn, Zn, $\mathrm{Cu}$ and $\mathrm{Mo}$ at $2,0.5,0.5,0.5,0.5$, and $0.1 \mathrm{mg} \cdot \mathrm{L}^{-1}$, respectively. The environment in the growth chamber was $25 \pm 2{ }^{\circ} \mathrm{C}$ air temperature, $70 \%$ relative humidity, $150 \mu \mathrm{mol} \cdot \mathrm{m}^{-2} \cdot \mathrm{s}^{-1} P P F$ with a 16-h photoperiod using metal halide and high-pressure sodium lamps. air $0.5 \mathrm{vvm}$ (air volume/culture volume, min) was supplied into the nutrient solution and the whole nutrient solution was exchanged after every $2 \mathrm{~d}$.

EXPERIMENT ON SOLUTION pH. pH of the nutrient solution in each plastic container was adjusted to $3,4,5,6$, and 7, respectively, while EC was maintained at $0.15 \mathrm{~S} \cdot \mathrm{cm}^{-1}$ in all treatments. $\mathrm{pH}$ was monitored every second day with a $\mathrm{pH}$ controller (Accumet 50, Fisher Scientific). The $\mathrm{pH}$ of the nutrient solution was adjusted with $0.1 \mathrm{~N} \mathrm{H}_{2} \mathrm{SO}_{4}$ and $\mathrm{NaOH}$. 
EXPERIMENT ON SOLUTION ELECTRICAL CONSUCTIVITY (EC). EC of the nutrient solution was adjusted to $0.08,0.15$, 0.22 and $0.36 \mathrm{~S} \cdot \mathrm{cm}^{-1} \cdot \mathrm{pH}$ was maintained at 6.0 which was determined to be optimum level in the previous experiments. EC was maintained by replacing the nutrient solution with fresh solution. For the EC adjustment, an equal amount of macronutrients and micronutrients were mixed in water by using a syringe (10 $\mathrm{mL})$. The $\mathrm{pH}$ and the $\mathrm{EC}$ of the nutrient solution were measured using a pH and EC controller (HM-20E CM-20E; TOA, Tokyo, Japan). The nutrient solution was changed for a new one every other day.

EXPERIMENT ONPPF. The environments in the growth chamber were maintained at $25 \pm 2{ }^{\circ} \mathrm{C}$ air temperature and $70 \%$ relative humidity. Cultures were maintained at three different levels of $P P F\left(50,150\right.$ and $\left.250 \mu \mathrm{mol} \cdot \mathrm{m}^{-2} \cdot \mathrm{s}^{-1}\right)$ with a 16 -h photoperiod using metal halide and high pressure sodium lamps. $P P F$ was measured (top of the plant canopy) with a data logger (LI-6400;
LI-COR, Lincoln, Nebr.). $\mathrm{CO}_{2}$ concentration inside the growth chamber was adjusted to either 350 (non-enrichment) or 1000 $\left(\mathrm{CO}_{2}\right.$ enrichment $) \mu \mathrm{mol} \cdot \mathrm{mol}^{-1}$. The flow of gas to each chamber was metered using glass flow meters and individual rates were maintained daily. The $\mathrm{CO}_{2}$ concentration inside the chamber was monitored just above crop canopy using an Infra red $\mathrm{CO}_{2}$ Analyzer (LI-COR, Inc, Lincoln, Nebr.). The $\mathrm{CO}_{2}$ monitored was calibrated using $\mathrm{CO}_{2}$ standard gas supplied by LICOR, Inc. $\mathrm{pH}$ and EC were maintained at 6.0 and $0.15 \mathrm{~S} \cdot \mathrm{cm}^{-1}$, respectively, which were determined to be the optimum levels in the previous experiments.

GROWTH AND PHOTOSYNTHESIS. Growth responses were measured after $28 \mathrm{~d}$ of culture in terms of fresh weight and dry weight of shoots and roots. The dry weight was determined after drying for $48 \mathrm{~h}$ at $70{ }^{\circ} \mathrm{C}$. Photosynthetic characteristics (rate of photosynthesis, stomatal conductance, transpiration and intercellular $\mathrm{CO}_{2}$ concentration) were measured in situ at $28 \mathrm{~d}$ after

Table 1. Growth characterstics of 'Atlantic' and 'Russet Burbank' potato as affected by $\mathrm{pH}$ and EC of the nutrient solution $28 \mathrm{~d}$ after planting in the hydroponic culture system.

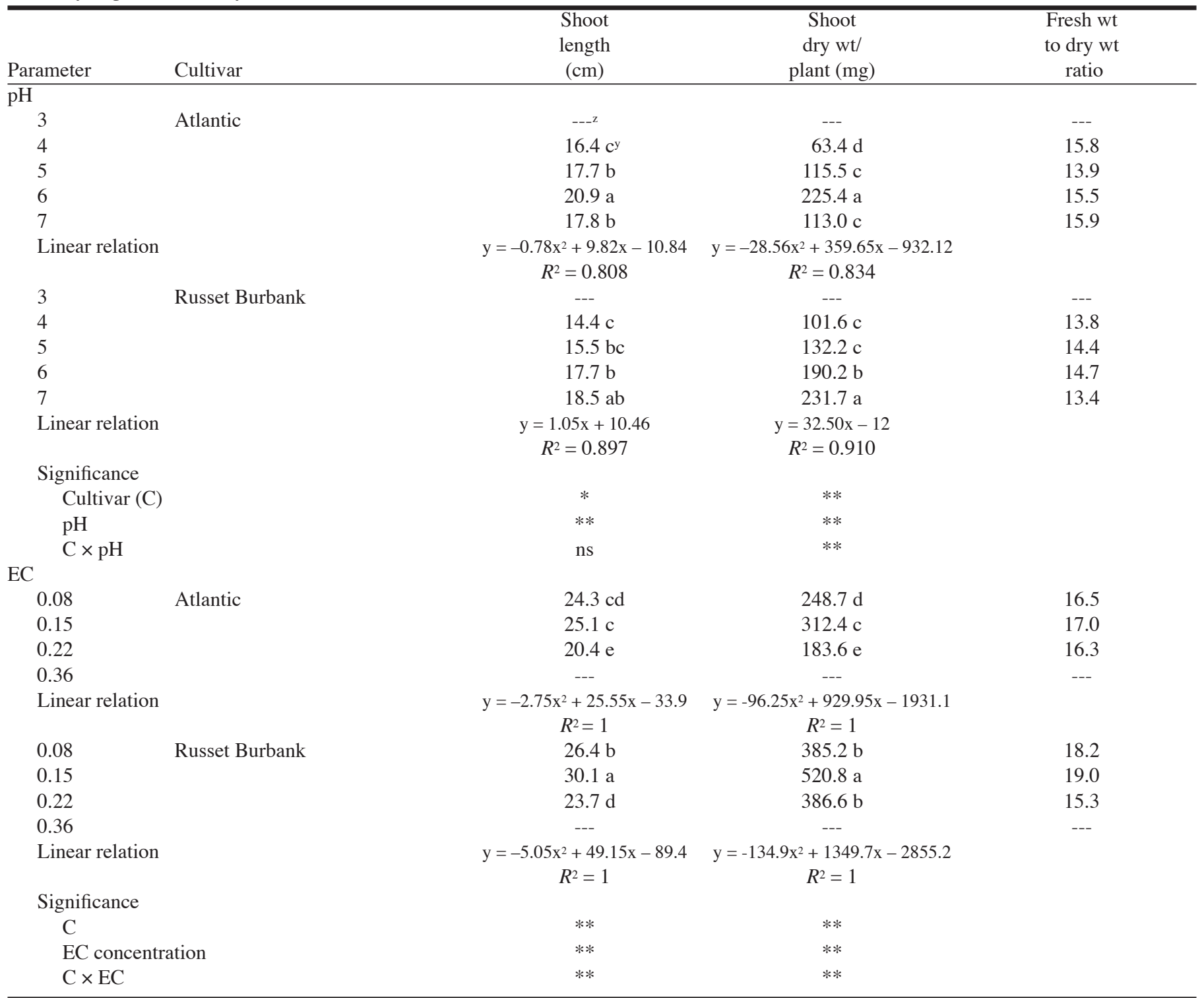

${ }^{\mathrm{z}}$ Not determined due to death of plantlets.

yValues within columns followed by the same letter are not different according to Duncan's multiple range test at $5 \%$ level.

ss,*,**Nonsignificant or significant at $P \leq 0.05$ or 0.01 , respectively. 
planting with a portable photosynthesis system (LI-6400, LI-COR Co., Lincoln Nebr.). Photosynthetic measurements were made between 1000 to $1200 \mathrm{HR}$ at the following conditions: light level was maintained at a $150 \mu \mathrm{mol} \cdot \mathrm{m}^{-2} \cdot \mathrm{s}^{-1} P P F, \mathrm{CO}_{2}$ concentration of the in-flow air was at $350 \mu \mathrm{mol} \cdot \mathrm{mol}^{-1}$, and RH at $60 \%$. Leaf temperature was $25^{\circ} \mathrm{C}$. Three plants were randomly selected and measurements were taken on three fully expanded leaves (third, fourth and fifth leaves from the top) using a standard leaf chamber having a $6 \mathrm{~cm}^{2}$ leaf area. Measurements were made in triplicate; there were three single-leaf replications within each treatment.

CHLOROPHYLl FLUORESCENCE. Chlorophyll fluorescence variables were measured in the abaxial side of freshly detached discs. Plants were kept for $30 \mathrm{~min}$ in the dark prior to measurement. Modulated fluorescence was measured using a PAM chlorophyll fluorometer (PAM-200; Heinz Walz, Effeltrich, Germany) connected with leaf clip holder (2030-B, Walz) and DA-200 (Walz) program for collection of data. Minimal fluorescence (Fo) was measured in 30-min dark-adapted leaves using light of $<0.1 \mu \mathrm{mol} \cdot \mathrm{m}^{-2} \cdot \mathrm{s}^{-1}$ and maximal fluorescence (Fm) was measured after a $1 \mathrm{~s}$ saturating pulse $\left(>3500 \mu \mathrm{mol} \cdot \mathrm{m}^{-2} \cdot \mathrm{s}^{-1}\right)$ in the same leaves. Maximal variable fluorescence $(\mathrm{Fv}=\mathrm{Fm}-\mathrm{Fo})$ and the photochemical efficiency of PSII ( $\mathrm{Fv} / \mathrm{Fm})$ were calculated for dark adapted leaves. In light adapted leaves, steady state fluorescence yield (Fs), maximal fluorescence $\left(\mathrm{F}^{\prime} \mathrm{m}\right)$ after a $1 \mathrm{~s}$ saturating pulse $\left(>3500 \mu \mathrm{mol} \cdot \mathrm{m}^{-2} \cdot \mathrm{s}^{-1}\right)$ and minimal fluorescence $\left(\mathrm{F}^{\prime} \mathrm{O}\right)$ were measured when actinic light was turned off. The fluorescence values measured in light adapted leaves were used to calculate the following parameters : variable fluorescence $\left(\mathrm{F}^{\prime} \mathrm{v}=\mathrm{F}^{\prime} \mathrm{m}\right.$ - Fo $)$, photochemical quenching $\left(\mathrm{q}_{\mathrm{P}}=\left(\mathrm{F}^{\prime} \mathrm{m}\right.\right.$ - Fs) $/ \mathrm{F}^{\prime} \mathrm{v}$, and non photochemical quenching $\left(\mathrm{q}_{\mathrm{N}}=1-\mathrm{F}^{\prime} \mathrm{v} / \mathrm{Fv}\right)$.

STATISTICS. Each of the treatments was performed three times and all the determinations were obtained with three randomly chosen plants. Statistical analyses were performed according to the SAS System (Version 6.21, SAS Institute Inc. Cary, NC.). Means and standard errors are used throughout, and the statistical significance between mean values was assessed using ANOVA or a Duncan's multiple range test. A probability of $P<0.05$ was considered significant.

\section{Results and Discussions}

Plantlet growth response (shoot length, total shoot and root fresh and dry weight) was greatest in nutrient solution of $\mathrm{pH} 6.0$ in case of 'Atlantic', while pH 7.0 was found to be best for 'Russet Burbank' (Table 1). All plantlets of both cultivars died in solutions at pH 3.0. Water content, represented by the ratio of fresh weight to dry weight, was constant in all the treatments. In general, optimum $\mathrm{pH}$ varied depending on plant species. It has been reported that the proper $\mathrm{pH}$ of the nutrient solution for most nutrient film technique (NFT) crops is 6.0 to 6.5 and 5.4 to 6.0 for substrate culture (Cooper,
1979; Fonteno, 1996; Schwarz, 1995). Similarly in chrysanthemum in microponic culture, $\mathrm{pH} 6.0$ resulted in highest growth rate (Hahn et al., 2000). Koyama et al. (2001) reported that root elongation of Arabidopsis thaliana is severely inhibited by low $\mathrm{pH}$ (4.5 to 4.8) and the growing root apex showed low viability. They suggested that the primary target of proton toxicity may be linked to a disturbance of the stability in the pectic polysaccharide network, where Ca plays a key role in plant roots, but the mechanism is still unclear. The effect of $\mathrm{pH}$ on cation and anion uptake are well known phenomena. At high $\mathrm{pH}$, a shift in the buffer system $\mathrm{CO}_{2} / \mathrm{H}_{2} \mathrm{CO}_{3} / \mathrm{HCO}_{3}{ }^{-}$in favor of $\mathrm{HCO}_{3}$ - impairs the efficiency of the proton-anion cotransport by consumption of protons in the apoplasm (Toulon et al., 1989). In our experiments, pH 6.0 to 7.0 proved to be the optimum level for potato plantlet growth in hydroponic culture.


Fig. 1. Net photosynthetic rate, stomatal conductance, transpiration rate and intercellular $\mathrm{CO}_{2}$ concentration in 'Atlantic' and 'Russet Burbank' potato plantlets as affected by EC $28 \mathrm{~d}$ after planting in the hydroponic culture system. Error bars represent the standard error of the mean $(n=3)$. 
Plantlet shoot length, total shoot and root fresh and dry weight were highest at EC $0.15 \mathrm{~S} \cdot \mathrm{cm}^{-1}$ for both cultivars, while EC 0.36 $\mathrm{S} \mathrm{cm}^{-1}$ was found to be lethal as all the plantlets died after $12 \mathrm{~d}$ of culture (Table 1).

Photosynthetic rate, stomatal conductance, and transpiration rate were also found to be affected by EC levels. An EC of 0.15 $\mathrm{S} \cdot \mathrm{cm}^{-1}$ resulted in the highest photosynthetic rate, stomatal conductance and transpiration rate, compared to other EC levels (Fig. 1). It appears that $\mathrm{EC}$ also affects internal $\mathrm{CO}_{2}$ concentrations and thus photosynthesis. The optimum EC of a balanced nutrient solution is generally known to be $0.15 \mathrm{~S} \cdot \mathrm{cm}^{-1}$ (Holder and Cristensen, 1988); however, optimum EC level was found to vary with plant species, season, growth stages and the quality of water (Hahn et al.,
2000). Schwarz (1995) reported that physiological disorders such as Ca deficiency could occur at high EC level. Growth depression may also originate from inhibited nutrient uptake, transport and use in the plants at high EC (Marschner 1995).

Chlorophyll fluorescence $(\mathrm{Fv} / \mathrm{Fm})$ reflects the maximal efficiency of excitation energy capture by open PSII reaction centers; a decrease in this parameter indicates down regulation of photosynthesis or photoinhibition (Maxwell and Johnson, 2000). Leaves of potato plantlets of both cultivars grown under higher EC levels showed a large decrease in this variable (Fig. 2). Both cultivars grown in nutrient solution with $0.15 \mathrm{~S} \cdot \mathrm{cm}^{-1} \mathrm{EC}$ showed a higher photochemical quenching $\left(\mathrm{q}_{\mathrm{p}}\right)$ and non-photochemical quenching $\left(\mathrm{q}_{\mathrm{N}}\right)$ than other treatments. $\mathrm{q}_{\mathrm{p}}$ indicates the proportion of PSII reaction centers that are open. Thus, $\mathrm{q}_{\mathrm{P}}$ and $\mathrm{Fv} / \mathrm{Fm}$ provide information about the underlying processes which have altered efficiency. A change in $\mathrm{q}_{\mathrm{p}}$ is due to closure of reaction centers, resulting from a saturation of photosynthesis by light. Changes in $\mathrm{q}_{\mathrm{N}}$ measure a change in the efficiency of heat dissipation, relative to the dark adapted state. Broadly, such an increase can occur as a result of processes that protect leaf from light-induced damage (Carvalho et al., 2001; Maxwell and Johnson, 2000). Therefore, the increase in $\mathrm{q}_{\mathrm{N}}$ in plants grown in nutrient solution of $0.15 \mathrm{~S} \cdot \mathrm{cm}^{-1} \mathrm{EC}$ may indicate an increase in the thermal dissipation in the PSII antennae related to an increased $\mathrm{pH}$ gradient, i.e., high energy state under the steady state of photosynthesis. Chlorophyll fluorescence measurements are extensively used now as a noninvasive method to investigate plant stress induced by high photon flux, heat, drought or various agents which affect the efficiency of the photosynthetic apparatus (Buschmann and Lichtenthaler, 1988). According to the modern formulation of this hypothesis, the intensity of chlorophyll fluorescence is affected by the redox state of the electron carrier $\mathrm{Q}_{\mathrm{A}}$, a plastoquinone that undergoes a one-electron photoreduction in the PSII reaction center. In light, the energy of antenna chlorophyll excited states is trapped by the $\mathrm{P} 680$ chlorophyll special pair of reaction centers and $Q_{A}$ is reduced by excited $P 680$ via a pheophytin molecule. Photochemical reactions in the reaction centers, leading to $Q_{A}$ reduction, compete with the dissipation of chlorophyll excited state energy through fluorescence emission. Therefore, reaction centers with oxidized $\mathrm{Q}_{\mathrm{A}}$ quench efficiently the fluorescence of PSII chlorophylls, whereas those with reduced $\mathrm{Q}_{\mathrm{A}}$ do not (Buschmann and Lichtenthaler, 1988). Our results indicate that higher susceptibility to photoinhibition in the plants grown under the higher EC levels was associated with more PSII reaction centers being inactivated due to higher proportion of the non- $\mathrm{Q}_{B}$-reducing PSII reaction centers. It has been shown that the key

Fig. 2. Chlorophyll fluorescence ratio $(\mathrm{Fv} / \mathrm{Fm})$, photochemical quenching $\left(\mathrm{q}_{\mathrm{P}}\right)$ and nonphotochemical quenching $\left(\mathrm{q}_{\mathrm{N}}\right)$ values in leaves of 'Atlantic' and 'Russet Burbank' potato as affected by EC of the nutrient solution $28 \mathrm{~d}$ after planting in the hydroponic culture system. Error bars represent the standard error of the mean $(\mathrm{n}=3)$. characteristics of these non- $\mathrm{Q}_{B}$-reducing centers is the inhibition of electron transport from $\mathrm{Q}_{\mathrm{A}}$ - to $\mathrm{Q}_{\mathrm{B}}$ (Franck et al., 2002). Greater accumulation of such non- $\mathrm{Q}_{\mathrm{B}}$-reducing centers in the plants grown under higher EC level inevitably leads to an increase in the fraction 
Table 2. Growth characterstics of 'Atlantic' and 'Russet Burbank' potato as affected by PPF $28 \mathrm{~d}$ after planting in the hydroponic culture system.

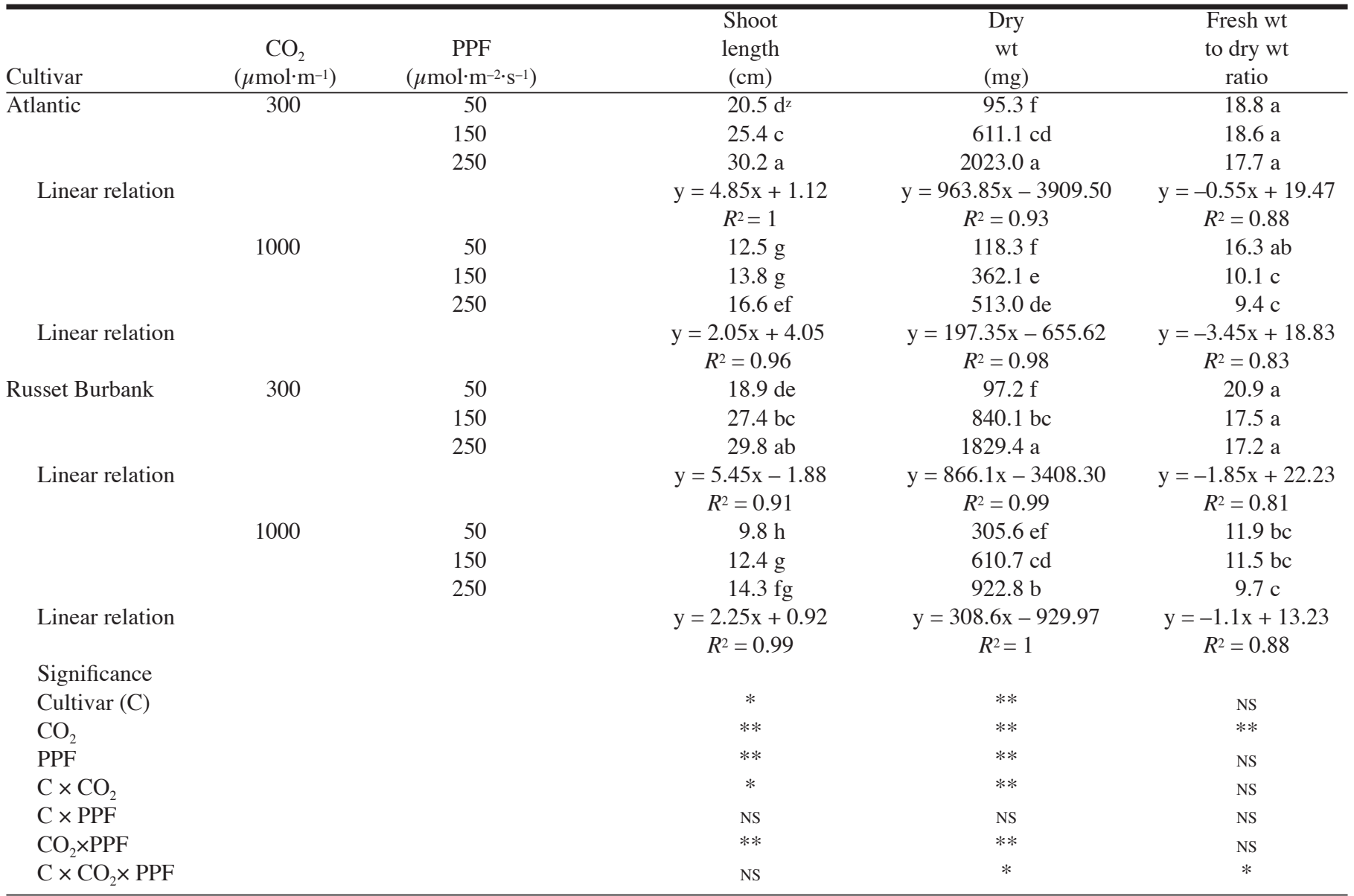

zMean separation within columns followed by the same letter are not different according to Duncan's multiple range test at 5\% level.

ss,****Nonsignificant or significant at $P \leq 0.05$ or 0.01 , respectively.

of reducing state of $\mathrm{Q}_{\mathrm{A}}$, thus, resulting in a lower $\mathrm{q}_{\mathrm{P}}$ as observed during photoinhibition. This increased fraction in the reducing state of $Q_{A}$ suggests that these plants were subjected to a higher pressure of excess exitation energy, which could potentially increase the probability of generating reactive radicals which can damage membrane components of PSII.

Increased growth and photosynthetic rates of potato plantlets of both cultivars were also observed under increasing $P P F$. Among the treatments, a $P P F$ of $250 \mu \mathrm{mol} \cdot \mathrm{m}^{-2} \cdot \mathrm{s}^{-1}$ resulted in the greatest increase in plant height, total shoot and root fresh weight, and dry weight (Table 2). Plantlets grown under these conditions also exhibited higher net photosynthetic rates regardless of the cultivars (Figs 3 and 4). However, an elevated $\mathrm{CO}_{2}$ concentration of $1000 \mu \mathrm{mol} \cdot \mathrm{mol}^{-1}$ significantly decreased the growth rate of the two potato cultivars, when they were grown under high $P P F$ conditions. In contrast, several researchers (Heo et al., 1996; Jeong et al., 1996; Kozai et al., 1992; Niu and Kozai; 1997; Seko and Kozai, 1996) concluded that high $P P F$ and $\mathrm{CO}_{2}$ enrichment drastically enhanced in vitro growth of carnation, cymbidium, turfgrass, and potato plantlets. The present study demonstrated that the $\mathrm{CO}_{2}$ enrichment condition with high PPF did not increase growth rate of potato plantlets as compared with that at a $P P F$ of $50 \mu \mathrm{mol} \cdot \mathrm{m}^{-2} \cdot \mathrm{s}^{-1}$ even under non $-\mathrm{CO}_{2}$ conditions. Although under optimal conditions, elevated $\mathrm{CO}_{2}$ increases photochemi-

Fig. 3. 'Atlantic' and 'Russet Burbank' potato plantlets as affected by $P P F$ levels $28 \mathrm{~d}$ after planting in the hydroponic culture system.
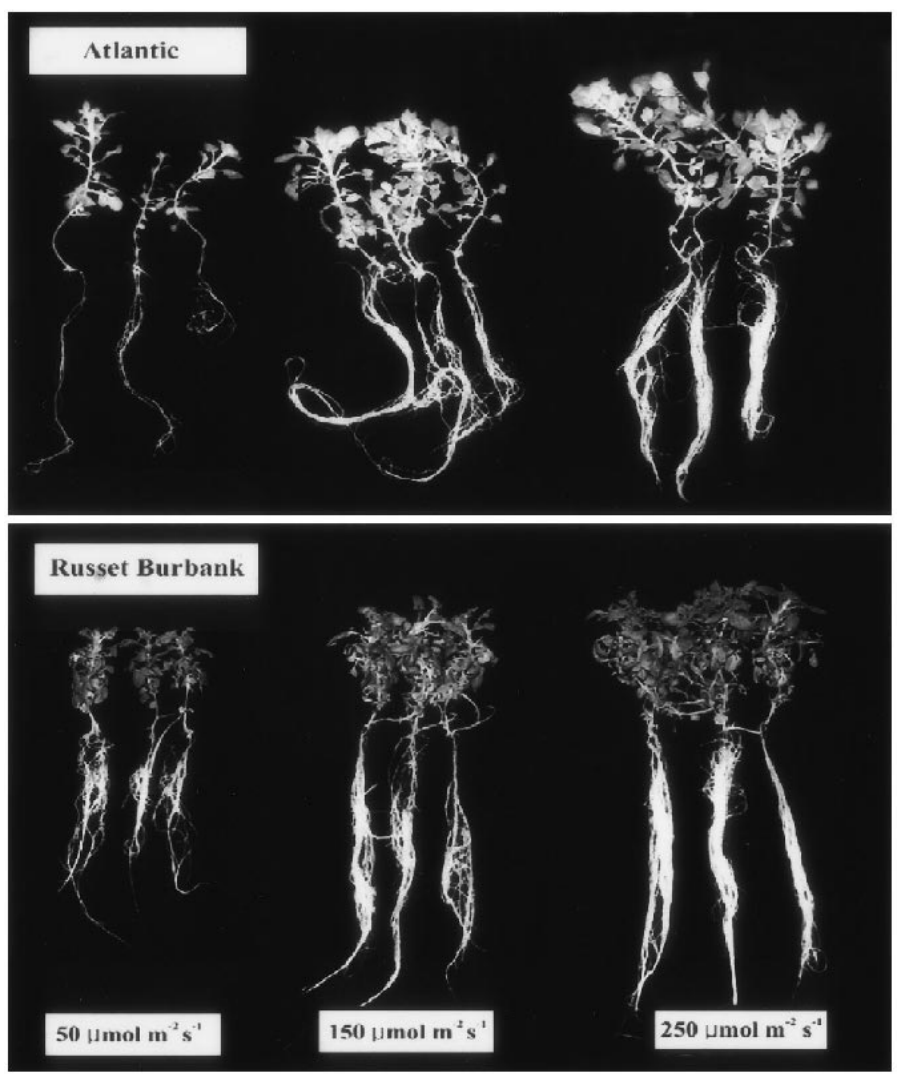


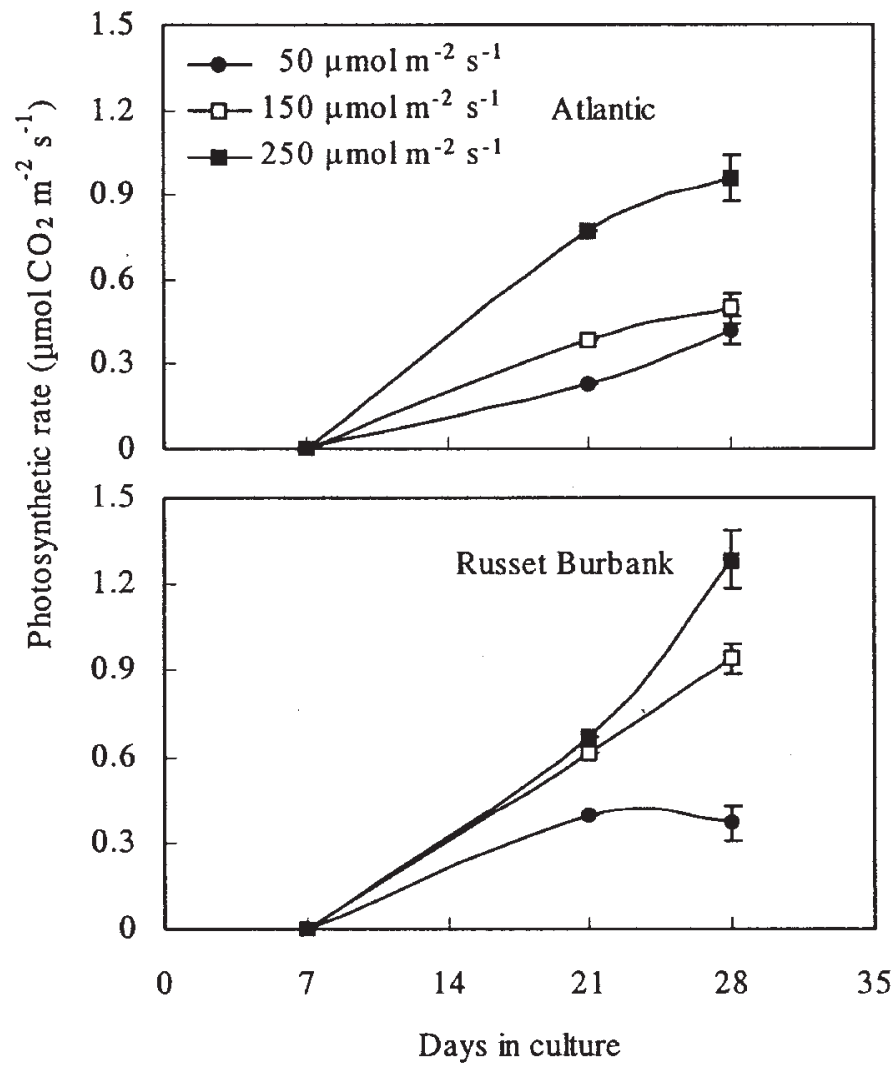

Fig 4. Photosynthetic rate in 'Atlantic' and 'Russet Burbank' potato plantlets as affected by $P P F$ levels $28 \mathrm{~d}$ after planting in the hydroponic culture system.

cal energy use and decreases the probability of photoinhibition, the reverse is true under limiting nitrogen conditions (Hymus et al., 2001). However, nitrogen limitation seems unlikely in hydroponic solutions which were replaced regularly. It has been widely regarded that the response of photosynthesis to increasing $\mathrm{CO}_{2}$ concentrations may be diminished by acclimation in these conditions (Hymus et al., 2001).

This experiment confirmed a direct relation of photosynthesis to growth, as affected by different EC levels of nutrient solution. We concluded that a smaller increase in biomass of potato plantlets grown in nutrient solutions with high EC levels was probably a result of down regulation of photosynthesis, as indicated by chlorophyll fluorescence. It is apparent from our study that nutrient solutions of $\mathrm{pH} 6.0$ and $0.15 \mathrm{~S} \cdot \mathrm{cm}^{-1} \mathrm{EC}$ are most suitable for growth of potato plantlets. Similarly, increasing the $P P F$ level had a more distinctive effect on plantlet growth than did $\mathrm{CO}_{2}$ enrichment. In conclusion, the results of this experiment demonstrate that optimal $\mathrm{pH}$ and $\mathrm{EC}$ level in combination with a high $P P F$ enhanced growth and acclimatization of potato plantlets grown hydroponically.

\section{Literature Cited}

Buchmann, C. and K. Lichtenthaler. 1988. Application of Chl fluorescence. Kluwer Academic Publishing, Dordrecht, The Netherlands.

Carvalho, L.C., M.L. Osorio, M.M. Chaveizats, and S. Amancio. 2001. Chlorophyll fluorescence as an indicator of photosynthetic functioning of in vitro grapevine and chestnut plantlets under ex vitro acclimatization. Plant Cell Tiss. Org. Cult. 67:271-280.

Cooper, A. 1979. The ABC of NFT. p. 36. Grower book, London.

Cui, Y.Y., E.J. Hahn, T, Kozai, and K.Y. Paek. 2000. Number of air exchanges, sucrose concentration, photosynthetic photon flux, and differences in photoperiod and dark period temperature affect growth of Rehmannia glutinosa plantlets in vitro. Plant Cell Tiss. Org. Cult. 62:219-226.

Fonteno, W.C. 1996. Growing media: types and physical/chemical properties, p. 93-122. In: D.W. Reed (ed.). Water, media and nutrition for greenhouse crops. Ball Publ., Batavia, Ill.

Franck, F., P. Juneau, and R. Popovic. 2002. Resolution of the photosystem I and photosystem II contributions to chlorophyll fluorescence of intact leaves at room temperature. Biochim. Biophys. Acta. 45206:1-8.

Hahn, E.J. and K.Y.Paek 2001. High photosynthetic photon flux and high $\mathrm{CO}_{2}$ concentration under increased number of air exchanges promote growth and photosynthesis of four kinds of orchid plantlets in vitro. In Vitro Cell Dev. Biol. Plant. 37:678-682.

Hahn, E.J., J.H. Bae, and Y.B. Lee. 2000. Growth and photosynthetic characterstics of chrysanthemum plantlets as affected by $\mathrm{pH}$ and $\mathrm{EC}$ of the nutrient solution in microponic culture. J. Kor. Soc. Hort. Sci. 41:12-15.

Heo, J.W., C. Kubota, and T. Kozai. 1996. Effects of $\mathrm{CO}_{2}$ concentration, PPF and sucrose concentration on Cymbidium plantlet growth in vitro. Acta Hort. 440:560-565.

Holder, R. and M.H. Cristensen. 1988. Effect of EC on the growth, yield and composition of cherry tomatoes grown in rockwool, $\mathrm{p}$. 213-227. ISOSC Proc. 7th Intl. Congr. Soilless Cult., Wageningen, The Netherlands.

Hymus, G.J., N.R. Baker, and S.P. Long. 2001. Growth in elevated $\mathrm{CO}_{2}$ can both increase and decrease photochemistry and photoinhibition of photosynthesis in a predictable manner. Dactylis glomerata grown in two levels of nitrogen nutrition. Plant Physiol. 127:1204-1211.

Jeong, B.R., C.S. Yang, and E.J. Lee. 1996. Photoautotrophic growth of Dianthus caryophyllus in vitro as affected by PPF and $\mathrm{CO}_{2}$ concentration. Acta Hort. 440:611-615.

Koyama, H., T. Toda, and T. Hara. 2001. Brief exposure to low pH stress causes irreversible damage to the growing root in Arabidopsis thaliana: pectin-Ca interaction may play an important role in proton rhizotoxicity. J. Expt. Bot. 355:361-368.

Kozai, T., K. Fujiwara, M. Hayashi, and C.J. Aitken. 1992. The in vitro environment and its control in micropropagation, p. 247-282. In: K. Kurata and T. Kozai (eds.). Transplant production systems. Kluwer Academic Publ., Dordrecht, The Netherlands.

Marschner, H. 1995. Mineral nutrition of higher plants. Academic press. London.

Maxwell, K. and G.N. Johnson. 2000. Chlorophyll fluorescence- practical guide. J. Expt. Bot. 51:659-678.

Niu, G. and T. Kozai. 1997. Simulation of the growth of potato plantlets cultured photoautotrophically in vitro. Trans. Amer. Soc. Agr. Eng. 40:255-260.

Piao, C.X. 2002. Effects of environmental factors on growth, tuberization and photosynthetic characterstics of in vitro and hydroponically grown potatoes. Ph D thesis. Chungbuk Natl. Univ., Korea.

Schwarz, M.. 1995. Nutrients, p. 7-32. In: B.L. McNeal, F. Tardieu, H. Van keulen, and D. Van Vleck (eds.). Soilless culture management. Springer-Verlag, Berlin.

Seko, Y. and T. Kozai. 1996. Effect of shading on photosynthesis of Coffea arabica. Jpn. J. Trop. Agr. 30:149-152.

Seon, J.H., Y.Y. Cui, T. Kozai, and K.Y. Paek. 2000. Influence of in vitro growth conditions on photosynthetic competence and survival rate of Rehmannia glutinosa plantlets during acclimatization period. Plant Cell Tiss. Org. Cult. 61:135-142.

Toulon, V., H. Sentenac, J.B. Thibaud, A. Soler, D.T. Clarkson, and C. Grignon. 1989. Effect of $\mathrm{HCO}_{3}{ }^{-}$concentration in the absorption solution on the energetic coupling of $\mathrm{H}^{+}$co-transport in roots of Zea mays L. Planta. 179:235-241.

Yamazaki, K. 1984. Comprehensive hydroponic culture. Hirotomo Publ. Co., Tokyo. p. 34-40.

Ziv, M. 1995. In vitro acclimatization, p. 493-516. In: J.A. Christie, T. Kozai, and M.L. Smith (eds.). Automation and environmental control in plant tissue culture. Kluwer Academic Publ., Dordrecht. The Netherlands. 